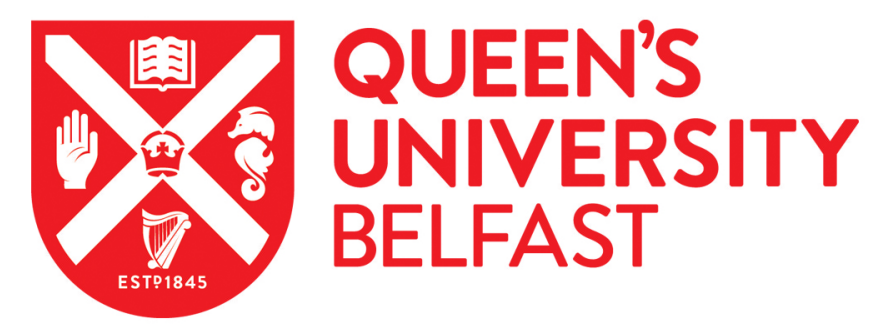

\title{
3D Efflux Velocity Characteristics of Marine Propeller Jets
}

Hamill, G. A., Kee, C., \& Ryan, D. (2015). 3D Efflux Velocity Characteristics of Marine Propeller Jets.

Proceedings of the ICE - Maritime Engineering, 168(2), 62-75. https://doi.org/10.1680/jmaen.14.00019

Published in:

Proceedings of the ICE - Maritime Engineering

Document Version:

Publisher's PDF, also known as Version of record

Queen's University Belfast - Research Portal:

Link to publication record in Queen's University Belfast Research Portal

Publisher rights

Copyright 2015 ICE Publishing: All rights reserved

\section{General rights}

Copyright for the publications made accessible via the Queen's University Belfast Research Portal is retained by the author(s) and / or other copyright owners and it is a condition of accessing these publications that users recognise and abide by the legal requirements associated with these rights.

Take down policy

The Research Portal is Queen's institutional repository that provides access to Queen's research output. Every effort has been made to ensure that content in the Research Portal does not infringe any person's rights, or applicable UK laws. If you discover content in the Research Portal that you believe breaches copyright or violates any law, please contact openaccess@qub.ac.uk. 


\section{Three-dimension efflux velocity characteristics of marine propeller jets}

\section{Gerard Hamill BSc, PhD}

School of Planning, Architecture and Civil Engineering, Queen's University Belfast, Northern Ireland

Charmaine Kee BEng, PhD

Hydro NI, Omagh Enterprise Centre, Omagh, Northern Ireland
Dona Ryan BEng, PhD, CEng, MICE, MIEI

Bellaghy, Co. Derry. Northern Ireland

Determining the efflux velocity in a ship's propeller jet is the key to calculating the velocity at any other location within the diffusing jet. Current semi-empirical equations used to calculate the magnitude of the efflux velocity have been based on studies that employed a limited range of propeller characteristics. This paper reports on the findings of an experimental investigation into the magnitude of the efflux velocities of the jets produced by four different propellers, where the characteristic of the blade geometry has been chosen to extend the range of applicability of the outcomes. Measurements of velocity have been made using a three-dimensional laser Doppler anemometry system, with the test propellers operating at a range of rotational speeds that bound typical operational values. Comparisons are made with current predictive theories and, to aid engineers in the design of marine infrastructure, methods are presented by which the three-dimensional efflux velocity components, as well as the resultant efflux value, can be more accurately determined.

\section{Notation}

$C_{\mathrm{t}} \quad$ thrust coefficient of propeller

$D_{\mathrm{h}} \quad$ diameter of hub (m)

$D_{\mathrm{p}} \quad$ diameter of propeller (m)

$E_{0} \quad$ gradient coefficient as defined in Equation 4

$L_{\mathrm{m}} \quad$ characteristic length (m)

$N \quad$ number of propeller blades

$n$

$P^{\prime}$

$R_{0}$

$R^{2}$

$\mathrm{R}_{\mathrm{e} \text { flow }}$

$\mathrm{R}_{\mathrm{e} \text { prop }}$

$R_{\mathrm{h}}$

$R_{\mathrm{m} 0}$

$R_{\mathrm{p}}$

$U_{0}$

$V_{0}$

$W_{0}$

X propeller speed of rotation $(\mathrm{r} / \mathrm{min})$

propeller pitch to diameter ratio

resultant velocity $(\mathrm{m} / \mathrm{s})$

coefficient of determination

Reynolds number of jet flow

Reynolds number of propeller

radius of propeller hub (m)

radial distance from propeller axis to location of efflux velocity $(\mathrm{m})$

radius of propeller $(\mathrm{m})$

maximum rotational velocity along efflux plane $(\mathrm{m} / \mathrm{s})$ maximum axial velocity along efflux plane $(\mathrm{m} / \mathrm{s})$ maximum radial velocity along efflux plane $(\mathrm{m} / \mathrm{s})$ Cartesian co-ordinate measured laterally from face of propeller (m)

Cartesian co-ordinate measured horizontally to left or right of propeller centreline $(\mathrm{m})$

Cartesian co-ordinate measured vertically up or down along propeller centreline $(\mathrm{m})$ $\varepsilon \quad$ gradient coefficient defined in Equation 3

$v \quad$ kinematic viscosity of fluid $\left(\mathrm{m}^{2} / \mathrm{s}\right)$

\section{Introduction}

A propeller is the most common form of marine propulsion device for ships and ferries. The impact of the turbulent highvelocity jets that are produced, by such devices, on the bed and banks of harbour basins and navigation channels can lead to serious erosion, structural undermining and costly remedial repairs. The continued mooring and unmooring of vessels at the same location can result in accumulative scour and siltation problems, as outlined by Sumer and Fredsoe (2002) and reported by Qurrain (1994). Froehlich and Shea (2000) have shown that essential cover to buried pipelines, tunnels and contained aquatic disposal sites can also be removed by propellerinduced flows. For these reasons, the effects of propellerinduced flow have received continuing worldwide attention.

The flow field produced by the action of rotating propeller blades is complex in nature. Near to the propeller, the passing blades and rotating hub influence the characteristics of the flow. The magnitude and distribution of the velocities within the dissipating jet are formulated at this initial 'efflux' plane and it is the magnitude of the maximum velocity along this plane, the 'efflux velocity', that is used by engineers in the calculation of all subsequent velocity values within the diffusing jet. 
The prediction of the efflux velocity has been reported by a number of authors such as Fuehrer and Römisch (1977), Berger et al. (1981), Verhey et al. (1987) and Hamill (1987), who have based their work on the concept of axial momentum theory to describe diffusion characteristics. Hamill et al. (2004) found the core assumptions of this theory inadequately described the process involved. More recently Lam et al. (2012a) described semi-empirical methods for predicting the efflux velocity of the main axial component of the flow, based on a range of experiments with one test propeller, while Lam et al. (2012b) extended the discussion by including measurements of turbulence intensity.

\section{Time-averaged velocity characteristics of unconfined propeller jets}

The jet produced by a rotating propeller is a complex threedimensional (3D) flow with axial, radial and rotational velocity components (Hamill et al., 2003). The axial velocity is the most significant component found along the propeller axis of rotation. It is this component that is used to impart a forward thrust to the ship. The axial thrust produced by a rotating propeller will depend on the propeller geometry excluding the hub, which does not provide any forward thrust (Hamill and Johnston, 1993). As the propeller jet diffuses, a second 'rotational' velocity component is developed due to the rotation of the blades. The propeller jet can be considered to act like any other submerged jet; as it moves through the receiving waters there is an exchange of energy with the surrounding fluid. As the surrounding fluid becomes entrained into the jet there is a loss in energy with the jet expanding in size; a third 'radial' component is developed due to the radial increase in the propeller jet (Hamill et al., 2003).
Figure 1 shows a schematic representation of the three components that make up the flow. On the vertical plane, ' $Z$ ', just behind the propeller, a vertical component of velocity can be seen to lie along the radius of the propeller, while on the horizontal plane, ' $\mathrm{Y}$ ', the same vertical component is tangential to the line of rotation at that point. The axial component is always located along the line of the propeller shaft. The combination of axial, radial and rotational velocity components make up the 3D flow, and the resultant velocity is found from the standard resolution of vectors in $3 \mathrm{D}$ space.

\subsection{Axial efflux velocity, $V_{0}$}

The maximum velocity taken from a time-averaged velocity distribution along the initial propeller plane is termed the efflux velocity, $V_{0}$, and it has been investigated by many researchers: Berger et al. (1981); Bergh and Cederwall (1981); Fuehrer and Römisch (1977); Hashmi (1993); Verhey (1983), Hamill (1987); Stewart (1992). Each have presented differing relationships that can be used to calculate the magnitude of the velocity, and the main equations that have been employed by the engineering community are summarised as follows.

Fuehrer and Römisch (1977)

1. $V_{0}=1.59 n D_{\mathrm{p}} \sqrt{C_{\mathrm{t}}}$

Hamill (1987)

$$
\text { 2. } V_{0}=1 \cdot 33 n D_{\mathrm{p}} \sqrt{C_{\mathrm{t}}}
$$

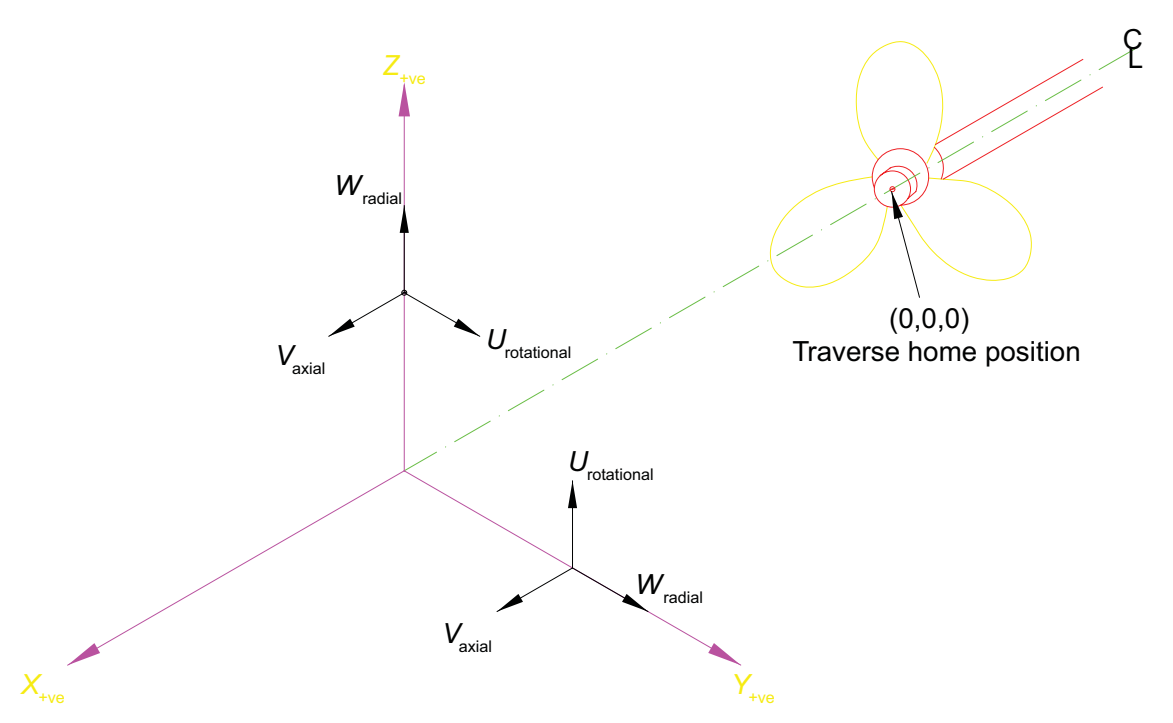

Figure 1. Schematic of velocity component directions 
Stewart (1992)

\section{3. $V_{0}=\varepsilon n D_{\mathrm{p}} \sqrt{C_{\mathrm{t}}}$}

where

$$
\varepsilon=D_{\mathrm{p}}^{-0.0686} P^{\prime 1.519} \mathrm{BAR}-0.323
$$

Hashmi (1993)

$$
\text { 4. } V_{0}=E_{0} n D_{\mathrm{p}} \sqrt{C_{\mathrm{t}}}
$$

where

$$
E_{0}=\left(\frac{D_{\mathrm{P}}}{D_{\mathrm{h}}}\right)^{-0.403}\left(C_{\mathrm{t}}\right)^{-1.79}(\mathrm{BAR})^{0.744}
$$

The distance to the maximum axial velocity (symbolised by $\left.R_{\mathrm{m} 0}\right)$ is the portion of the blade where maximum thrust occurs. Berger et al. (1981) proposed the maximum axial velocity on the propeller efflux plane occurred at a position $R_{\mathrm{m} 0}$ given by

$$
\text { 5. } \quad R_{\mathrm{m} 0}=0.67 R_{\mathrm{p}}-R_{\mathrm{h}}
$$

where $R_{\mathrm{p}}$ and $R_{\mathrm{h}}$ are the radius of the propeller and hub, respectively.

McGarvey (1996) found the output solutions of Equation 5 differed from the results of an empirical investigation by up to $30 \%$. Prosser (1986) suggested the maximum velocity in the jet occurred at approximately $60 \%$ of the blade radius from the propeller centreline, due to the low blade velocities at the hub, which produce less thrust. Work by Hamill et al. (2004) found the axial velocity distribution to increase from the propeller hub to a distance of approximately $0 \cdot 7 R_{\mathrm{p}}$ along the blade before decreasing towards the blade tips.

\subsection{Rotational efflux velocity, $U_{0}$}

The rotating effect of a ship's propeller causes the water to move spirally in the direction of flow about the axis of rotation, thereby containing a significant 'swirl' velocity component (Brewster, 1997). The direction of the rotationally induced flow is in the direction of rotation of the propeller blades.

The axial component of velocity was found to be the largest contributor to the resultant velocity field in the propeller wash followed in turn by the rotational and radial components (Brewster, 1997). Prosser (1986) found the magnitude of the rotational velocity was approximately $30 \%$ of the maximum axial velocity along the initial efflux plane.

To date, limited experimental investigations have been carried out examining the characteristics of the swirl, or rotational, component. Petersson et al. (1996) investigated the swirling jet produced by an impeller and measured the rotational component of velocity up to 12 impeller diameters from the rotating blades. It was suggested that the rotational component of velocity influenced the diffusion of the jet in the axial direction and similar effects can be observed in the wash produced by a marine propeller. Brewster (1997) analysed the characteristics of the rotational component based on a computational fluid dynamics (CFD) simulation.

Both Petersson et al. (1996) and Brewster (1997) observed similar trends in the rotational velocity distributions along the efflux plane. The rotational velocity profile showed two peak velocity values. One peak corresponded to the point at which the hub and the propeller blades were joined and the other was located at a point near to the tip of the propeller. Petersson et al. (1996) measured the first peak at $0 \cdot 15 r / R_{\mathrm{p}}$ and the second peak at $0 \cdot 65 r / R_{\mathrm{p}}$ from the propeller centreline. Brewster (1997) found these two peak velocities to occur at $0 \cdot 3 r / R_{\mathrm{p}}$ and $0 \cdot 8 r / R_{\mathrm{p}}$.

\subsection{Radial efflux velocity, $W_{0}$}

McGarvey (1996) carried out an experimental investigation to measure the magnitude of the radial velocity within the jets produced by two differing propellers. Previous researchers assumed the radial component of velocity was negligible within the wash of a marine propeller. However, McGarvey (1996) found the magnitude of this component was approximately $30 \%$ of the axial velocity along the face of the propeller and concluded that it should not be neglected. Brewster (1997) extracted radial velocity measurements from CFD results in order to investigate the characteristics of this component.

\section{Experimental set-up}

A non-intrusive optical measurement system was used to acquire the axial, radial and rotational velocity components produced by a range of test propellers operating under bollardpull conditions. Each propeller was investigated at four differing speeds of rotation set to values that bounded typical operational values. All experiments were carried out in a freesurface tank, large enough to allow the unhindered expansion of the propeller jets investigated.

\subsection{Selection of propellers}

British Maritime Technology (BMT) SeaTech Limited provided on loan two four-bladed experimental propellers for this research: $92 \mathrm{~mm}$ and $103 \mathrm{~mm}$ in diameter. Two further propellers of $76 \mathrm{~mm}$ and $131 \mathrm{~mm}$ in diameter were also tested. 


\begin{tabular}{lllccc} 
& & Prop 1 & Prop 2 & Prop 3 & Prop 4 \\
\hline Propeller diameter & $D_{\mathrm{p}}: \mathrm{mm}$ & 76 & 92 & 103 & 131 \\
Hub diameter & $D_{\mathrm{h}}: \mathrm{mm}$ & $14 \cdot 92$ & $20 \cdot 32$ & $20 \cdot 5$ & $27 \cdot 2$ \\
Thrust coefficient & $C_{\mathrm{t}}$ & 0.402 & 0.2908 & 0.388 & 0.558 \\
Pitch to diameter ratio & $P^{\prime}$ & $1 \cdot 0$ & 0.735 & 0.8283 & $1 \cdot 136$ \\
Blade area ratio & BAR & 0.47 & 0.4525 & 0.6417 & 0.922 \\
Rake angle & $\circ$ & 0 & 10 & 0 & 0 \\
Number of blades & $\mathrm{N}$ & 3 & 4 & 4 & 6
\end{tabular}

Table 1. Propeller geometric characteristics

Each of the propellers investigated varied in size as well as having differing numbers of blades $(N)$, pitch to diameter ratios $\left(P^{\prime}\right)$, thrust coefficients $\left(C_{\mathrm{t}}\right)$, rake and blade area ratios (BARs) (Table 1). The number of propeller blades varies from three to six. The pitch to diameter ratio ranges from a minimum of 0.735 up to a maximum of $1 \cdot 0$. The thrust coefficient, at zero advance speeds, ranges from 0.2908 up to 0.558 . The BARs vary from of 0.4525 to 0.922 . The blades of the $76 \mathrm{~mm}, 103 \mathrm{~mm}$ and $131 \mathrm{~mm}$ dia. propellers have no forward inclination; that is, all blades are at $90^{\circ}$ angles to the hub while the blades of the 92 $\mathrm{mm}$ dia. propeller are inclined by a further $10^{\circ}$. In selecting these propellers it was intended to test over a large practical variation of characteristics typical of sea-going vessels, and provide a thorough test for the current predictive theories.

Froudian scaling was used to determine the speeds of rotation tested. It has been established by Blaauw and van de Kaa (1978) that scale effects due to viscosity can be ignored if the Reynolds number for the propeller exceeds $7 \times 10^{4}$ and the Reynolds number for the propeller flow is greater than $3 \times 10^{3}$. The Reynolds number for the jet flow is given by

6. $\mathrm{R}_{\mathrm{e} \text { flow }}=\frac{V_{0} D_{\mathrm{p}}}{v}$

The Reynolds number for the propeller is given by

7. $\quad \mathrm{R}_{\text {eprop }}=\frac{n D_{\mathrm{p}} L_{\mathrm{m}}}{v}$

The characteristic length, $L_{\mathrm{m}}$, depends on the BAR, propeller and hub diameters as well as the number of blades. Blaauw and van de Kaa (1978) defined this length term as follows

8. $L_{\mathrm{m}}=(\mathrm{BAR}) D_{\mathrm{p}} \pi\left(2 N\left(1-\frac{D_{\mathrm{h}}}{D_{\mathrm{p}}}\right)\right)^{-1}$
The rotational speeds used in the programme of work were based on standard Froudian scale calculations for a generic propeller of $2.5 \mathrm{~m}$ in diameter, rotating at $200 \mathrm{r} / \mathrm{min}$, and having a thrust coefficient of $0 \cdot 35$. This provided target speeds for the experimental propellers (1-4) of 990, 1056, 865 and $640 \mathrm{r} / \mathrm{min}$, respectively. The propellers were operated across a range of speeds that bounded these target values, and these are listed in full in Table 2.

The Reynolds numbers for the propellers operating at these rotational speeds ranged from $1.4 \times 10^{4}$ to $7 \cdot 7 \times 10^{4}$, while the Reynolds numbers for the propeller jet ranged from $5.3 \times 10^{4}$ to $30 \times 10^{4}$ (Table 2). The Reynolds numbers for the propellers were, in some cases, slightly less than $7 \times 10^{4}$; however, Blaauw and van de Kaa (1978) and Verhey (1983) proposed these scale

\begin{tabular}{lcrc}
\hline $\begin{array}{l}\text { Propeller } \\
\text { diameter: } \mathrm{mm}\end{array}$ & $\begin{array}{c}\text { Propeller speed } \\
\text { of rotation: } r \text { /min }\end{array}$ & \multicolumn{1}{c}{$\mathrm{R}_{\mathrm{e} \text { flow }}$} & $\mathrm{R}_{\mathrm{e} \text { prop }}$ \\
\hline 76 & 750 & $6.4 \times 10^{4}$ & $1.9 \times 10^{4}$ \\
& 1000 & $8.6 \times 10^{4}$ & $2.6 \times 10^{4}$ \\
& 1250 & $10.7 \times 10^{4}$ & $3.2 \times 10^{4}$ \\
& 1500 & $12.8 \times 10^{4}$ & $3.9 \times 10^{4}$ \\
92 & 500 & $5.3 \times 10^{4}$ & $1.4 \times 10^{4}$ \\
& 750 & $7.9 \times 10^{4}$ & $1.7 \times 10^{4}$ \\
& 1000 & $10.7 \times 10^{4}$ & $2.3 \times 10^{4}$ \\
103 & 1250 & $13.3 \times 10^{4}$ & $3.5 \times 10^{4}$ \\
& 500 & $5.7 \times 10^{4}$ & $2.4 \times 10^{4}$ \\
& 750 & $8.5 \times 10^{4}$ & $3.7 \times 10^{4}$ \\
& 1000 & $11.4 \times 10^{4}$ & $4.9 \times 10^{4}$ \\
131 & 1250 & $14.2 \times 10^{4}$ & $6.1 \times 10^{4}$ \\
& 350 & $10.5 \times 10^{4}$ & $2.7 \times 10^{4}$ \\
& 500 & $14.9 \times 10^{4}$ & $3.8 \times 10^{4}$ \\
& 750 & $22.5 \times 10^{4}$ & $5.7 \times 10^{4}$ \\
& 1000 & $29.9 \times 10^{4}$ & $7.7 \times 10^{4}$
\end{tabular}

Table 2. Propeller speeds of rotation and corresponding Reynolds numbers investigated 
effects would be insignificant. The Reynolds numbers for the jets were all greater than $3 \times 10^{3}$ for the speeds of rotation investigated satisfying the criteria for Froudian scaling.

\subsection{Data acquisition system}

Laser Doppler anemometry (LDA) is a well-established nonintrusive technique by Yeh and Cummins (1964) for the measurement of fluid flow. The 3D LDA adopted in this research was a Dantec Dynamics three-component backscatter system with a water-cooled Stabilite 2017 5W Argon-Ion laser manufactured by Spectra Physics as the illuminating light source. Frequency shifting of $40 \mathrm{MHz}$ using a Bragg cell was used to remove directional ambiguity in the velocity measurements.

The optical probe was mounted on an automatic Dantec Dynamics 3D-traverse with measurement accuracies within $\pm 0.05 \mathrm{~mm}$ in three orthogonal directions. The measurement volume was located at a distance of $240 \mathrm{~mm}$ from the LDA probe. Three-dimensional LDA configurations required the transformation of measurements made in a non-orthogonal coordinate system into a Cartesian system. The transformation of measurements was carried out each time the laser was setup.

The LDA technique indirectly measures the velocity of the flow by measuring the speed of the (seeding) particles suspended in the flow. The seeding material used in this study was non-spherically shaped polyamide particles having a mean particle size of $20 \mu \mathrm{m}$ and density of $1.03 \mathrm{~g} / \mathrm{cm}^{3}$.

All measurements were made in fully coincident mode; that is, all three processors had to recognise a valid data point before accepting the data. The maximum data rates were determined by the rates obtained with the lowest power channel. Data rates ranged between a minimum of 30 and a maximum of 1000 particles per second.

An experimental grid was established at which velocity readings across the face of the efflux plane could be taken. The centre of the propeller hub, at the cutting edge of the propeller blades, was taken as the zero location and measurements were taken on a Y (horizontal), Z (vertical) grid in 2-5 mm steps.

\section{Efflux velocity measurements}

All velocity components within the propellers jets were recorded simultaneously using the LDA equipment. Analysis of the 3D flow field as well as each of the components parts was then undertaken.

\subsection{Axial efflux velocity}

Figures 2-5 show the distribution of the axial component of velocity across the efflux plane for all tests undertaken. The shape of these profiles follows the expected trends and the efflux velocity, $V_{0}$, is taken as the average of the two peak velocities found on either side of the jet centreline, for each respective speed of rotation. The magnitudes of the efflux velocity produced during these tests can be seen in Table 3 .

Comparisons of the measured empirical results were made with the output solutions of Equations 1-4 when used to predict the magnitude of the maximum axial velocity along the efflux plane (Figures 6-9). Equation 1, derived from the actuator disc theory, was found to predict the efflux velocity within $10 \%$ of the measured values. Equation 2 suggested by Hamill (1987), having a lower efflux coefficient of $1 \cdot 33$, was found to

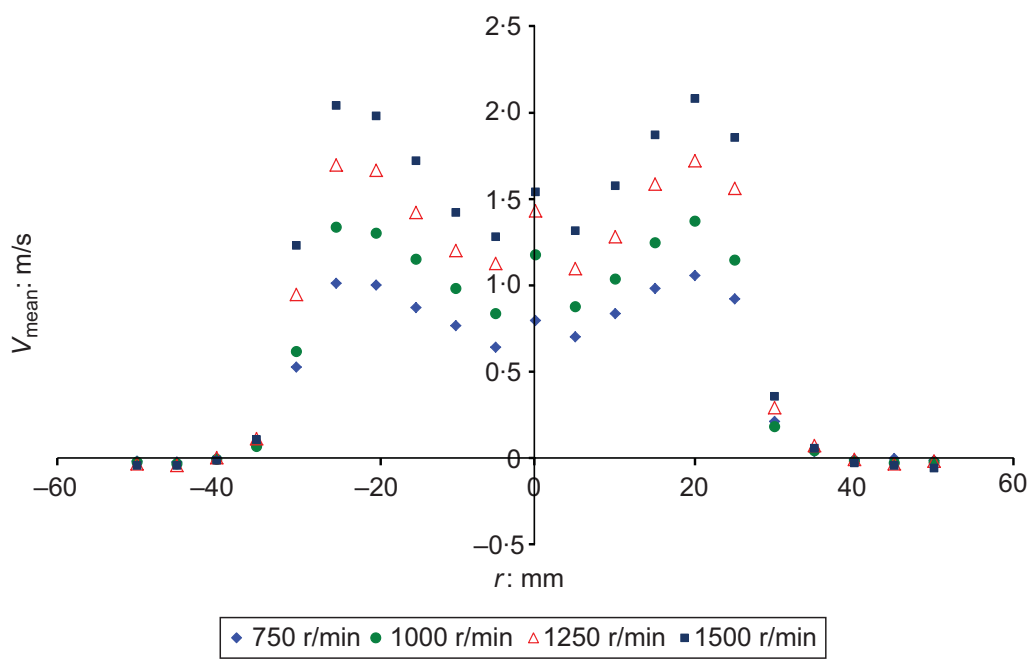

Figure 2. Axial velocity distributions on efflux plane: propeller 1 


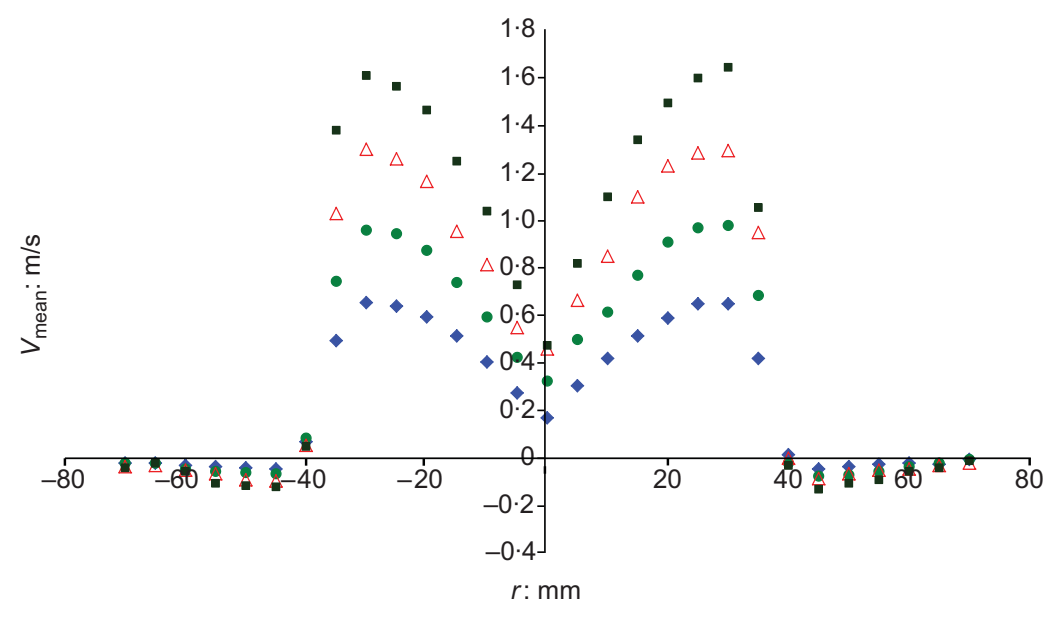

$\bullet 500 \mathrm{r} / \mathrm{min} \quad \bullet 750 \mathrm{r} / \mathrm{min} \Delta 1000 \mathrm{r} / \mathrm{min} \quad-1250 \mathrm{r} / \mathrm{min}$

Figure 3. Axial velocity distributions on efflux plane: propeller 2

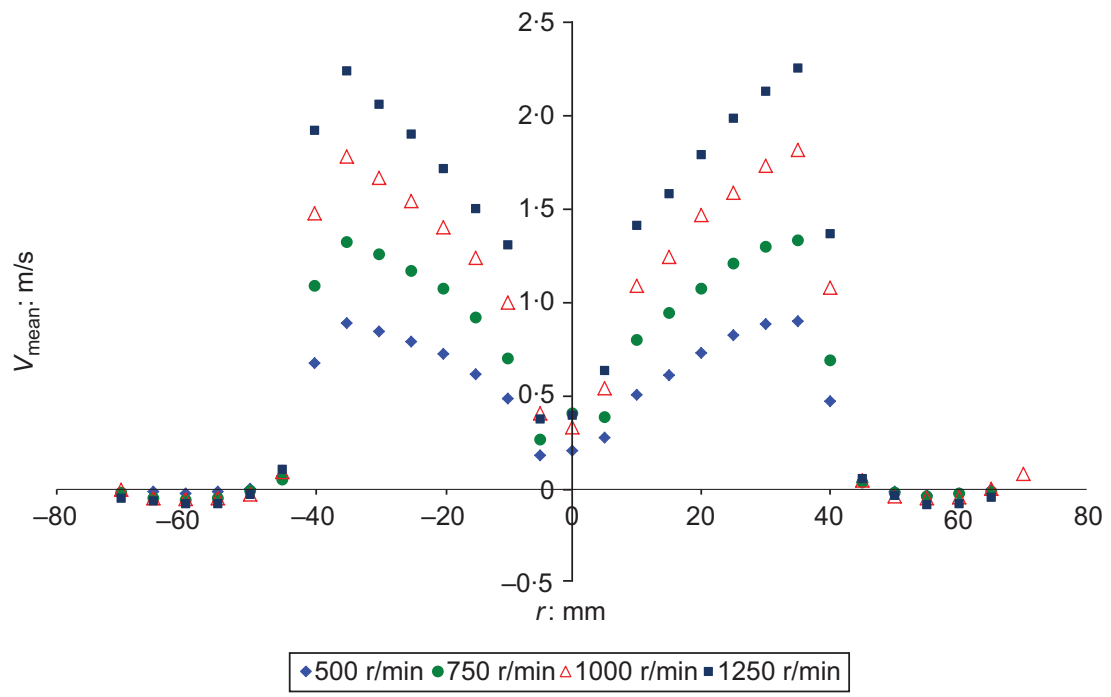

Figure 4. Axial velocity distributions on efflux plane: propeller 3

underestimate the measured efflux velocities by up to $20 \%$. Equations 3 and 4 proposed by Stewart (1992) and Hashmi (1993), respectively, were found to underestimate the experimental efflux velocities by up to $40 \%$. It is clear that the derivation of such semi-empirical equations from narrow test ranges, results in high errors when used to extrapolate beyond the range from which they have been derived.

A stepwise multivariate analysis of the main variables within the investigation showed that the main characteristics of influence to the axial efflux velocity were the speed of rotation $(n)$, propeller diameter $\left(D_{\mathrm{p}}\right)$, thrust coefficient $\left(C_{\mathrm{t}}\right)$, the same variables used by all previous authors adopting the momentum theory approach. Both linear and non-linear regression algorithms were used to establish a relationship with $V_{0}$ and Equation 9 was developed, giving a coefficient of determination of $R^{2}=0.997$.

9. $V_{0}=1 \cdot 22 n^{1.01} D_{\mathrm{p}}^{0.84} C_{\mathrm{t}}^{0.62}$ 


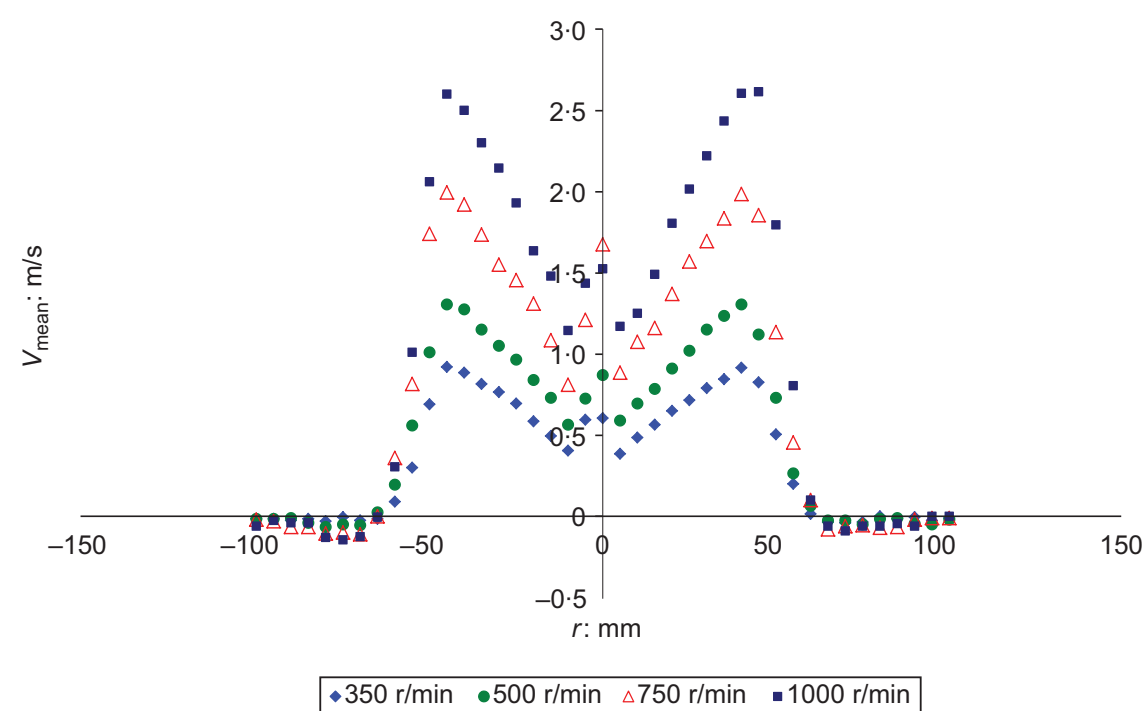

Figure 5. Axial velocity distributions on efflux plane: propeller 4

\begin{tabular}{lrcccl}
\hline r/min & $\begin{array}{c}\text { Axial: } \\
\mathrm{m} / \mathrm{s}\end{array}$ & $\begin{array}{c}\text { Rotational: } \\
\mathrm{m} / \mathrm{s}\end{array}$ & $\begin{array}{c}\text { Radial: } \\
\mathrm{m} / \mathrm{s}\end{array}$ & $\begin{array}{c}\text { Resultant: } \\
\mathrm{m} / \mathrm{s}\end{array}$ \\
\hline Propeller 1 & 750 & 1.033 & 0.780 & 0.230 & 1.124 \\
& 1000 & 1.353 & 1.115 & 0.287 & 1.606 \\
& 1250 & 1.708 & 1.265 & 0.343 & 1.87 \\
& 1500 & 2.060 & 1.460 & 0.400 & 2.205 \\
Propeller 2 & 500 & 0.653 & 0.400 & 0.140 & 0.702 \\
& 750 & 0.970 & 0.550 & 0.245 & 1.045 \\
& 1000 & 1.298 & 0.770 & 0.300 & 1.391 \\
& 1250 & 1.628 & 1.055 & 0.365 & 1.765 \\
Propeller 3 & 500 & 0.890 & 0.710 & 0.165 & 0.931 \\
& 750 & 1.325 & 0.960 & 0.235 & 1.391 \\
& 1000 & 1.798 & 1.385 & 0.310 & 1.848 \\
& 1250 & 2.248 & 1.655 & 0.435 & 2.305 \\
Propeller 4 & 350 & 0.918 & 0.63 & 0.155 & 0.977 \\
& 500 & 1.305 & 1.31 & 0.26 & 1.5 \\
& 750 & 1.990 & 1.765 & 0.375 & 2.169 \\
& 1000 & 2.603 & 2.26 & 0.465 & 2.897
\end{tabular}

theory (Equation 5). The experimental ratio of $R_{\mathrm{m} 0} / R_{\mathrm{p}}$ for each of the test propellers was found to be $0.592,0.652,0.6796$ and 0.6489 . Therefore the location of $R_{\mathrm{m} 0}$ ranged between $0.59 R_{\mathrm{p}}$ and $0.68 R_{\mathrm{p}}$ across the propeller radius. Percentage differences of $20 \%, 31 \%, 31 \%$ and $29 \%$ were found between the empirical results and the output solutions of Equation 5. These percentage differences, of up to $31 \%$, indicate that Equation 5 is inaccurate in determining $R_{\mathrm{m} 0}$. On average the maximum velocity was found to occur at approximately $65 \%$ of the blade radius from the centre of the propeller. No consistent comparisons were found between the location of the maximum axial velocity and the location of the maximum blade area, blade thickness or chord lengths along equivalent propeller radii.

\subsection{Rotational efflux velocity}

The rotational velocity distribution taken along the initial efflux plane showed two peak velocity values. One peak corresponded to the point at which the hub and the propeller blades were joined and the other was present at a point near to the tip of the propeller. This distribution was evident for all experimental propellers tested and agrees with the findings of Brewster (1997) and Petersson et al. (1996). Figures 10 shows a plot of the distribution of measured velocity for test propeller 4, and is typical of that found for all propellers in this investigation.

It is proposed that in all future investigations, where the propeller characteristics lie within the ranges tested in this study, the efflux velocity is calculated using Equation 9.

Table 4 shows the corresponding measured radial locations of the efflux velocity compared to those predicted from current

In comparison to the axial efflux velocity, the rotational efflux was between $0 \%$ and $43 \%$ of the axial value and on average it was $25 \%$ lower (Table 3 ). This is a significant difference from the magnitudes found by Prosser (1986) who claimed the values were on average $70 \%$ lower. Investigations into the magnitudes of the consistently smaller second peak showed a 


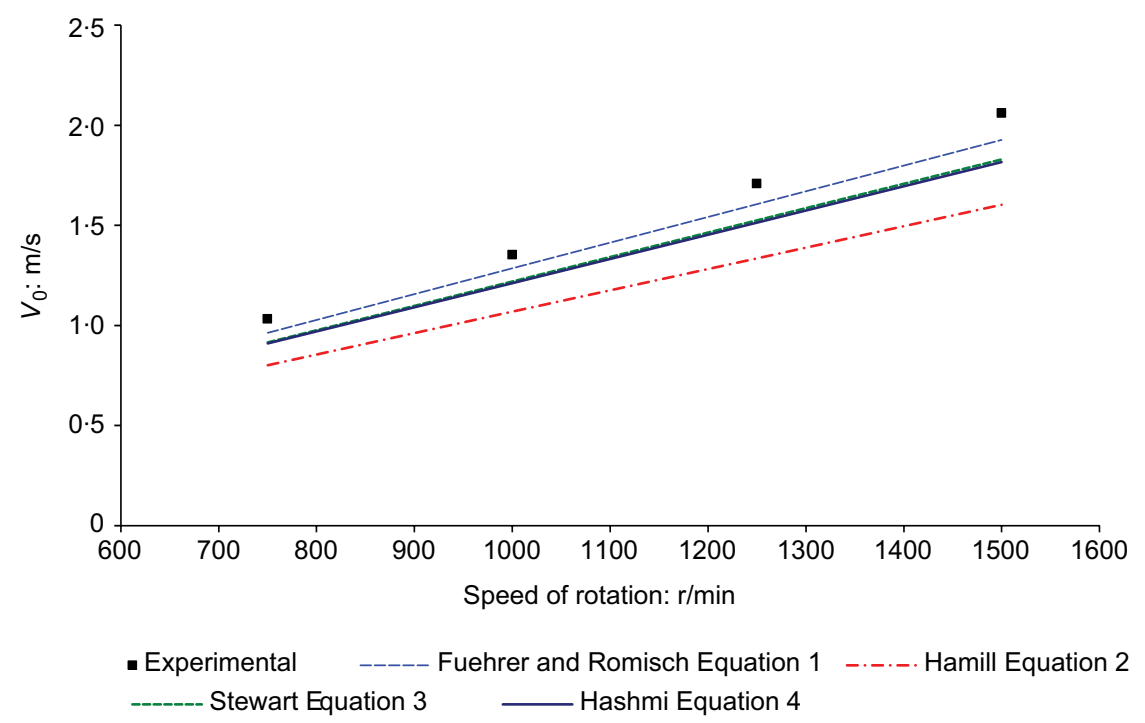

Figure 6. Comparison between measured and predicted axial efflux velocity: propeller 1

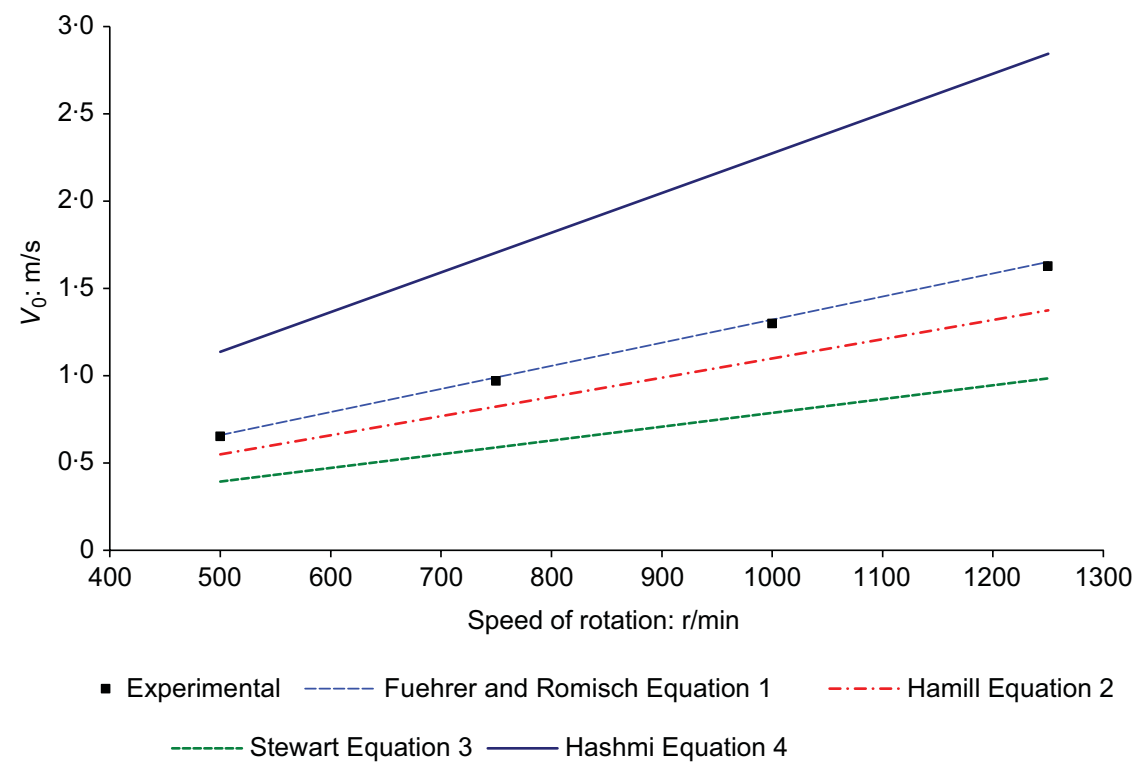

Figure 7. Comparison between measured and predicted axial efflux velocity: propeller 2

percentage difference of the same order of magnitude as that proposed by Prosser.

No existing equations are available to predict the magnitude of the maximum rotational velocity $\left(U_{0}\right)$ along the efflux plane. A stepwise variable selection process was used to examine the influence of the independent variables in the study. The results of this analysis indicated that the variables that were most likely to influence the maximum rotational velocity, were the propeller speed of rotation $(n)$, propeller diameter $\left(D_{\mathrm{p}}\right)$ and thrust coefficient $\left(C_{\mathrm{t}}\right)$, the same set of variables that control the magnitude of the axial component. 


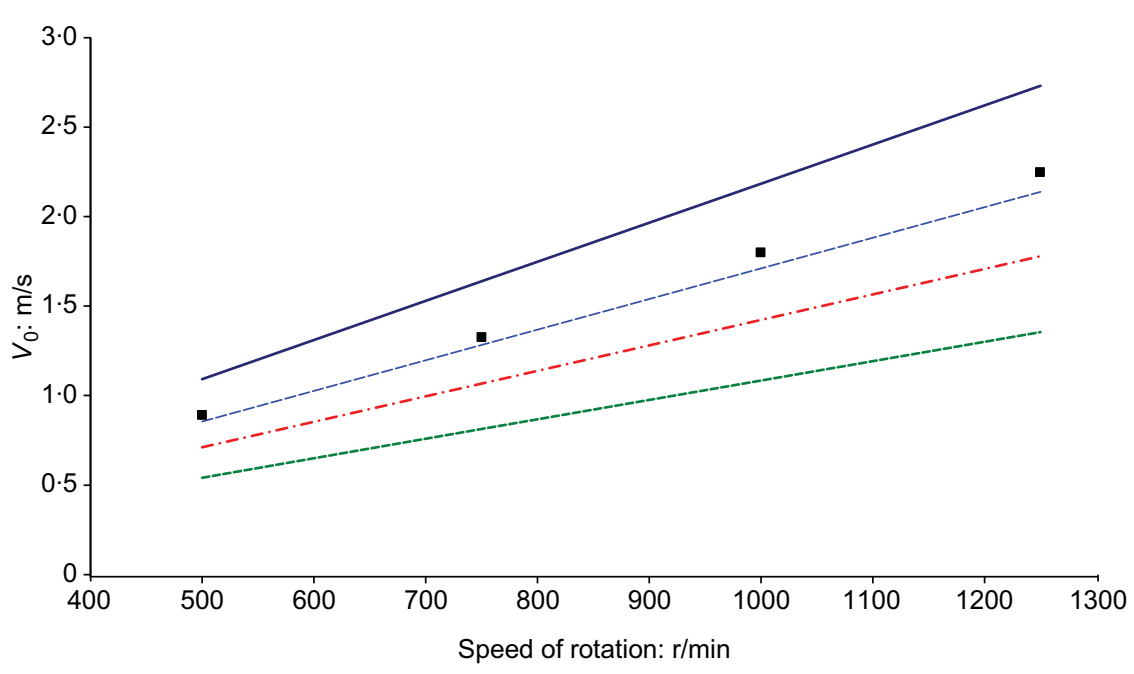

- Experimental ----- Fuehrer and Romisch Equation 1 -.... Hamill Equation 2

Figure 8. Comparison between measured and predicted axial efflux velocity: propeller 3

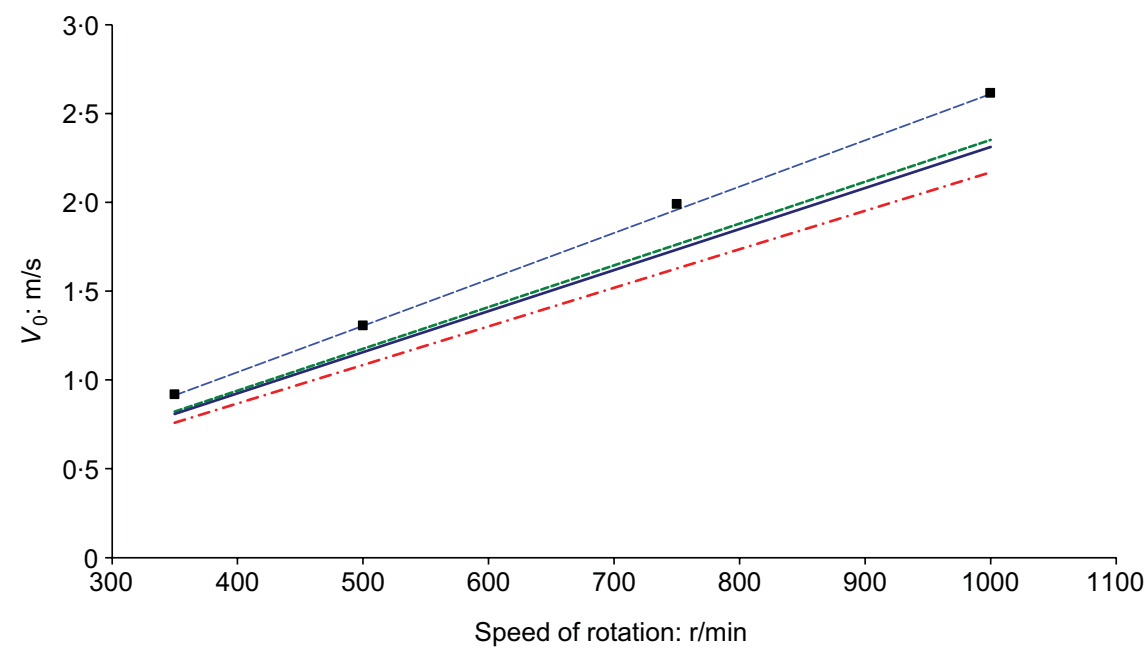

- Experimental ----- Fuehrer and Romisch Equation 1 -.-.-. Hamill Equation 2 Stewart Equation $3 \longrightarrow$ Hashmi Equation 4

Figure 9. Comparison between measured and predicted axial efflux velocity: propeller 4

The correlation of these three independent variables on the dependent variable, $U_{0}$, was $R^{2}=0.982$; the overall stepwise analysis can be found in Table 5, and Equation 10 is proposed as the most suitable equation for calculating the rotational efflux velocity.

10. $U_{0}=1 \cdot 23 n^{1.05} D_{\mathrm{p}}^{0.798} C_{\mathrm{t}}^{1.186}$ 
The output solution of Equation 10 was plotted and compared with the measured efflux velocities and can be found in Figure 11, providing good comparisons across the full range of tested propellers.

Both Petersson et al. (1996) and Brewster (1997) investigated rotational velocity distributions along the initial efflux plane. The rotational velocity profile was shown to have two peak velocity values. One peak corresponded to the point at which the hub and the propeller blades were joined and the other was present at a point near to the tip of the propeller. Petersson et al. (1996) measured the first peak at $0 \cdot 15 r / R_{\mathrm{p}}$ and the second peak at $0.65 \mathrm{r} / R_{\mathrm{p}}$ from the propeller centreline. Brewster (1997) found the two peak velocities occurred at $0 \cdot 3 r / R_{\mathrm{p}}$ and $0 \cdot 8 r / R_{\mathrm{p}}$ from the propeller centreline.

\begin{tabular}{|c|c|c|}
\hline $\begin{array}{l}\text { Propeller } \\
\text { radius } R_{\mathrm{p}}= \\
D_{\mathrm{p}} / 2: \mathrm{mm}\end{array}$ & $\begin{array}{l}\text { Experimental } R_{\mathrm{mo}}: \mathrm{mm} \\
\text { (Average } R_{\mathrm{mo}} \text { taken } \\
\text { from left and right of } \\
\text { propeller jet centreline) }\end{array}$ & $\begin{array}{l}\text { Predicted } R_{\mathrm{mo}}: \mathrm{mm} \\
\text { (Equation } 5 \\
\text { proposed by Berger } \\
\text { et al. (1981)) }\end{array}$ \\
\hline 38 & $22 \cdot 5$ & $20 \cdot 46$ \\
\hline 46 & 30 & 24.01 \\
\hline $51 \cdot 5$ & 35 & $27 \cdot 64$ \\
\hline $65 \cdot 5$ & $42 \cdot 5$ & 34.77 \\
\hline
\end{tabular}

Table 4. Comparison of calculated and empirical measurements of the location of the maximum axial velocity along the efflux plane, $R_{\mathrm{mo}}$
The measured locations of the peak velocities along the propeller hub/blade interface and near the propeller blade tip were found on average to give the position of the maximum rotational velocity at $r / R_{\mathrm{p}}=0 \cdot 12$, corresponding to the propeller hub/blade interface, and the second peak was located at approximately $75 \%$ from the propeller centreline: that is, $r / R_{\mathrm{p}}$ $=0.74$. This is in agreement with Petersson for the main peak location and between the proposed values of Petersson and Brewster for the second peak.

\subsection{Radial efflux velocity}

McGarvey (1996) found the magnitude of this component was approximately $30 \%$ of the axial velocity along the efflux plane.

\begin{tabular}{llll}
\hline Model & \multicolumn{1}{c}{ Variables entered } & \multicolumn{1}{c}{$R^{2}$} & Error (SSE) \\
\hline 1 & $C_{\mathrm{t}}$ & 0.434 & 0.15069 \\
2 & $n, C_{\mathrm{t}}$ & 0.866 & 0.07604 \\
$\mathbf{3}$ & $\boldsymbol{n}, \boldsymbol{D}_{\mathbf{p}}, \boldsymbol{C}_{\mathbf{t}}$ & $\mathbf{0 . 9 8 2}$ & $\mathbf{0 . 0 2 9 0 3}$ \\
4 & $n, D_{\mathrm{p}}, C_{\mathrm{t}}, \mathrm{BAR}$ & 0.98 & 0.0303 \\
5 & $n, D_{\mathrm{p}}, C_{\mathrm{t}}, \mathrm{BAR}, P^{\prime}$ & 0.98 & 0.032 \\
6 & $n, D_{\mathrm{p}}, C_{\mathrm{t}}, \mathrm{BAR}, P^{\prime}, \mathrm{N}$ & 0.859 & 0.171
\end{tabular}

Note: bold values indicate the selected output obtained from a stepwise regression analysis of all test variables.

Table 5. Stepwise model summary for rotational efflux velocity

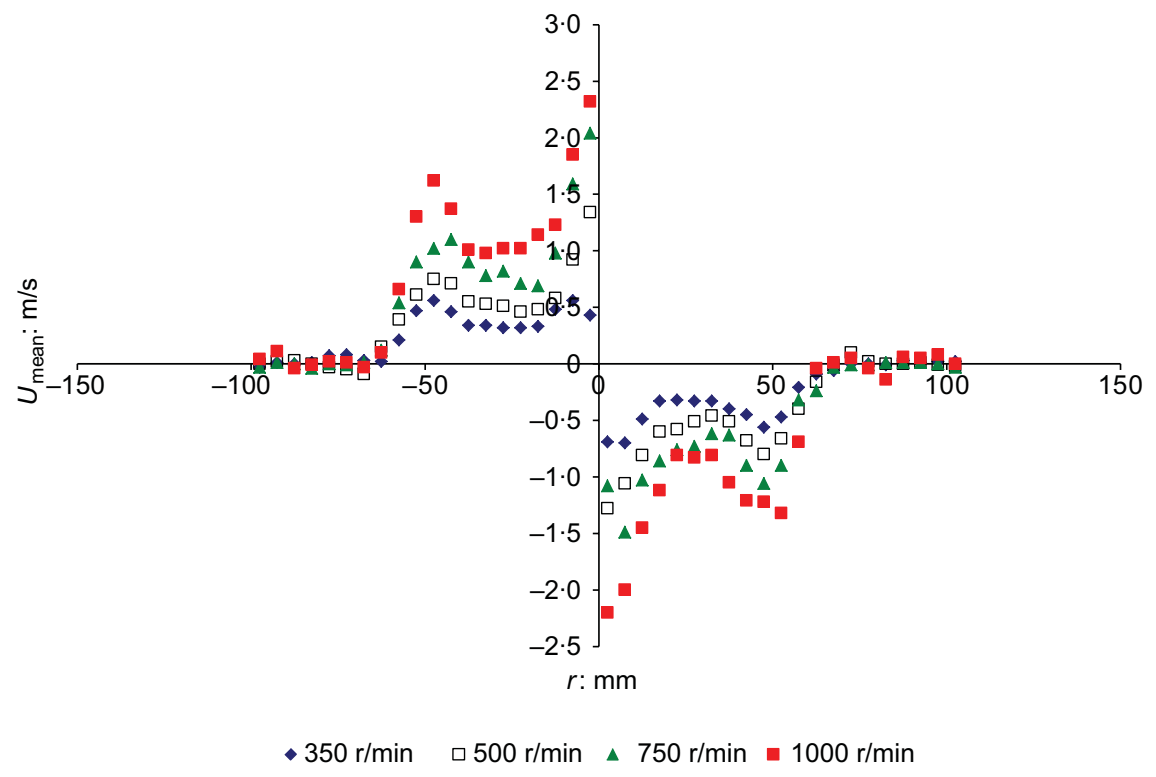

Figure 10. Rotational velocity distribution on efflux plane:

propeller 4 


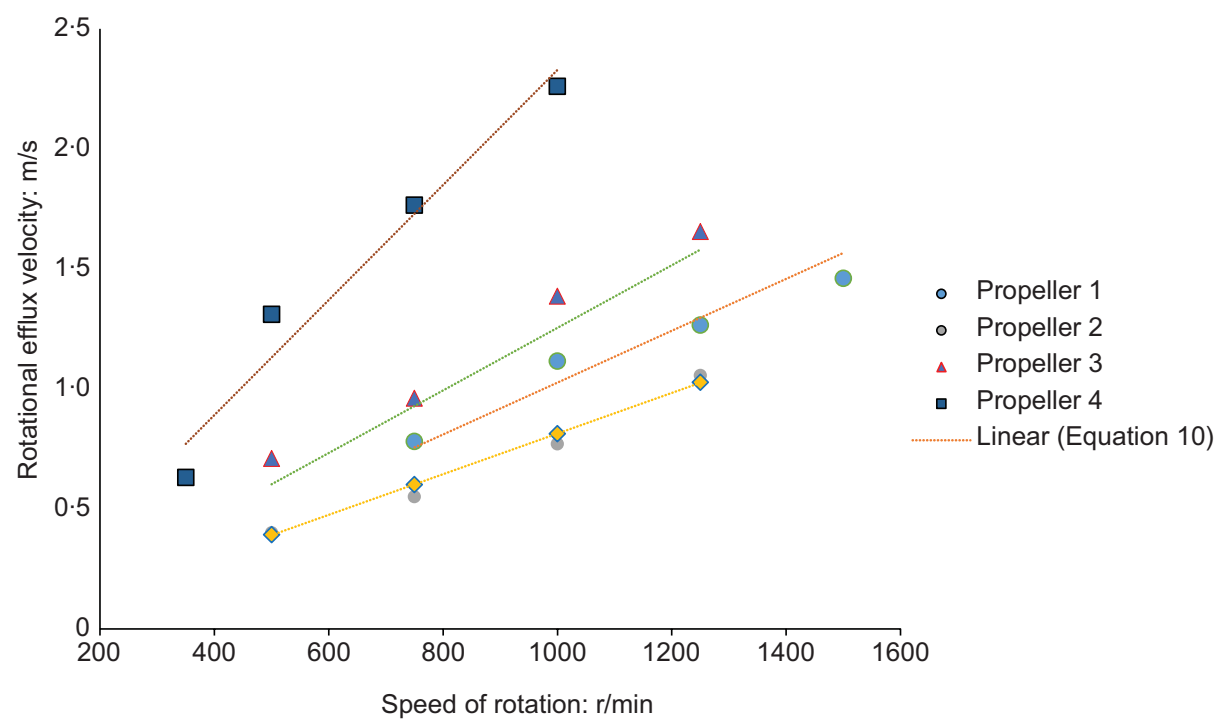

Figure 11. Comparison of measured rotational efflux velocity and Equation 10

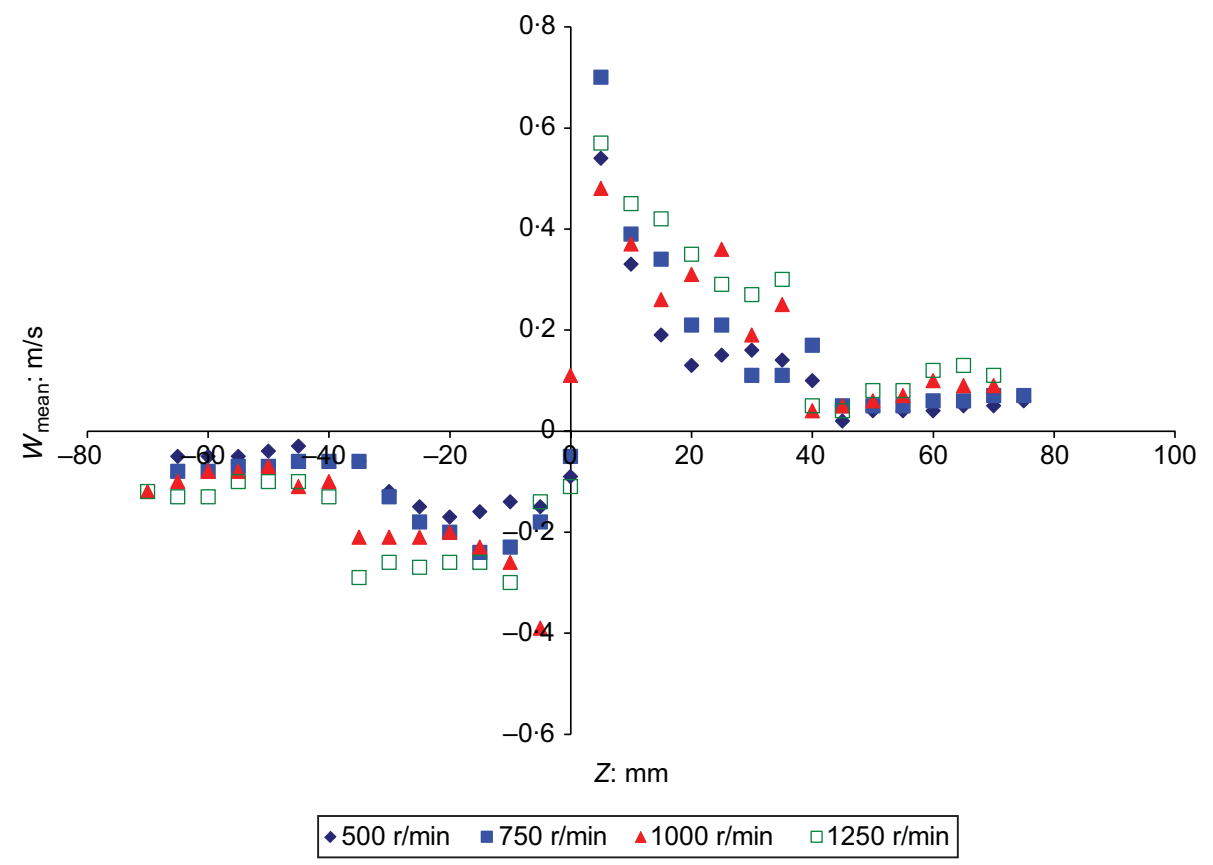

Figure 12. Radial velocity distributions on efflux plane: propeller 3

This magnitude of the radial velocity had a significant effect on the direction and diffusion of the jet flow within the initial stages of jet development. Table 3 shows the measured values of all the efflux velocities obtained in this investigation and it can be seen that the radial efflux velocity was consistently $20 \%$ of the maximum axial efflux value. Figure 12 shows the velocity distribution of the radial component of velocity, at all tested speeds, for propeller 3 , and is again typical of the output obtained for each test propeller. As is the case of the rotational component the velocity direction can be seen to 
change signs as it crosses through the propeller centre, with flow always occurring away from the centrepoint.

Examination of the literature showed no existing equations were available to determine the magnitude of the radial efflux velocity, $W_{0}$. In a manner similar to that employed for the previous components, Equation 11 was developed to allow a calculation to take place, and for which the coefficient of determination was $0 \cdot 964$.

$$
\text { 11. } W_{0}=0 \cdot 153 n^{0.986} D_{\mathrm{p}}^{0.719} C_{\mathrm{t}}^{0.344}
$$

\subsection{Resultant velocity}

Figure 13 shows the resultant velocity profiles across the efflux plane for test propeller 2, and these are typical of the results obtained for all propellers. The shape of the distribution follows a trend similar to that of the axial efflux velocity across the propeller blade, with values beyond the hub increasing to a maximum, typical at $0 \cdot 6 R_{\mathrm{p}}$, and then decreasing rapidly to the jet edge. The large resultant component at the hub is due to the large rotational component found at that location. Outside that zone the direction of the resultant velocity is determined by the dominance of the axial and rotational velocities, and a $3 \mathrm{D}$ vector plot of the resultant velocity, Figure 14, shows output that clearly shows the swirling nature of the jet, a significant departure from the typical momentum jet. The magnitude of the efflux resultant is, in the cases of propellers 1,2 and 4 , approximately $7-9 \%$ larger than the axial value (propeller 3 was typically $2-4 \%$ larger than its efflux). The measured values appear on Table 3 alongside the component efflux values. Analysis of the resultant velocity and its dependence on the test variables reveals an expression similar in form to those derived for the other components, Equation 12. This equation has a standard error of 0.0112 and an $R^{2}$ value of 0.997.

12. $R_{0}=1 \cdot 2 n 0 \cdot 994 D_{\mathrm{p}}^{0.741} C_{\mathrm{t}}^{0.711}$

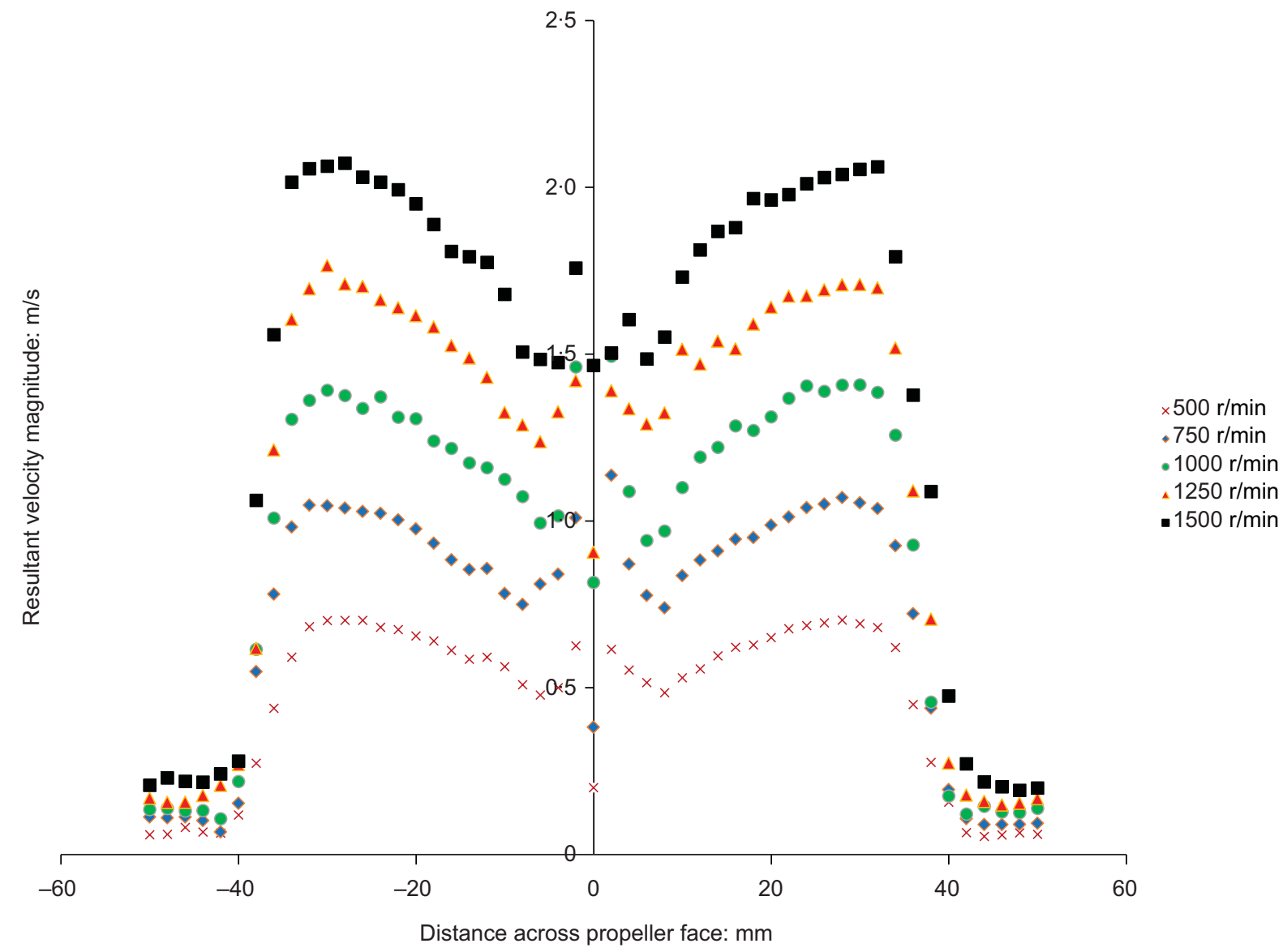

Figure 13. Distribution of the magnitude of the resultant velocity for propeller 2 


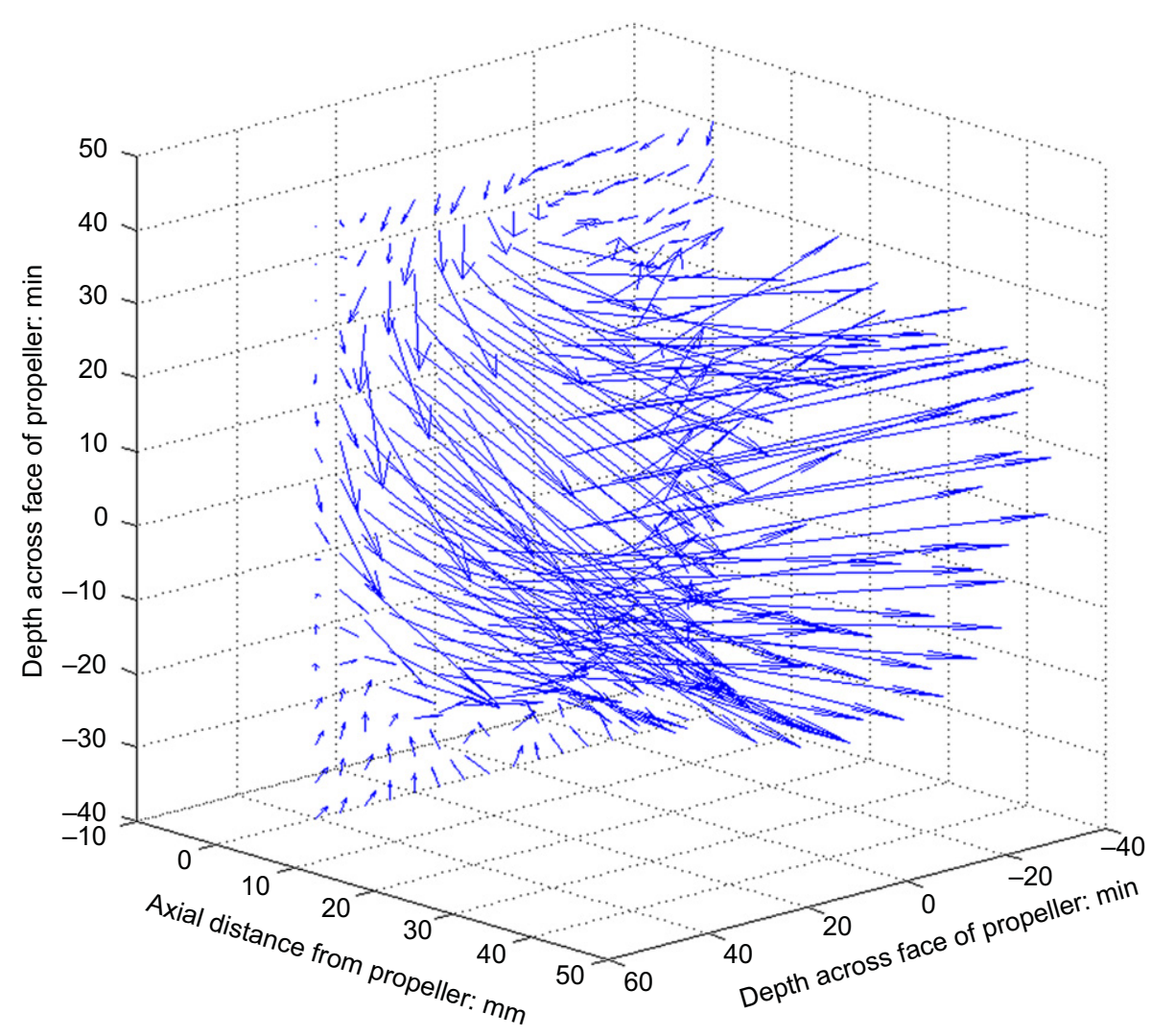

Figure 14. 3D resultant velocity distribution across efflux plane for propeller 2

\section{Conclusion}

The 3D nature of the efflux velocity was investigated for four propellers, whose characteristics ranged across typical operational values, using a 3D LDA measurement system over a very fine grid. The propellers were operated over a range of speeds of rotations typical of standard ship operating speeds.

The magnitude of a predicted axial efflux velocity was found to be dependent on the speed of rotation, propeller size and operating thrust coefficient. Comparison of measurements to current prediction methods found that while current methods predicted velocities well in some circumstances, as those equations were developed from limited test ranges, errors were present. A more general expression was derived, based on the extended test programme in this study, and it is recommended that it should be used in future calculations by design engineers.

The efflux rotational velocity was found to have two peak values on either side of the axis of rotation. Agreement with previous researchers was found with regards to the peak value at the hub edge; however, the peak value across the blade profile was found to occur at $75 \%$ of the propeller radius. The magnitude of this value was found to be some $70 \%$ of the axial value, $40 \%$ higher than previously thought, and for the first time an equation has been proposed that will allow the magnitude to be determined. The radial component, the smallest of all three components and some $20 \%$ of the axial value, was investigated and, as for the other major components, a method of prediction proposed.

The paper presents, for the first time, a discussion of the resultant velocity at efflux. The propeller jet on the efflux plane has measurable swirl, and the magnitude of the resultant component was found to be typically $8 \%$ higher than the standard calculated axial value. Calculations of the resultant efflux velocity should be made using the equation developed in the paper.

\section{REFERENCES}

Berger W, Felkel K, Hager M, Oebius H and Schale E (1981)

Courant provoquè par les bateaux. Protection des berges et solution pour èviter l'èrosion du lit Haut Rhin.

Proceedings of the 25th Congress on Permanent 
International Association of Navigation Congresses (PIANC), Edinburgh, UK, Section I-1, pp. 51-69 (in French).

Bergh H and Cederwall K (1981) Propeller Erosion in Harbours. Hydraulics Laboratory, Royal Institute of Technology, Stockholm, Sweden, bulletin no. TRITA-VBI-107, pp. 139-143.

Blaauw HG and van de Kaa EJ (1978) Erosion of Bottom and Sloping Banks Caused by the Screw Race of Manoeuvring Ships. Delft Hydraulics Laboratory, Delft, the Netherlands, publication no. 202, pp. 1-12.

Brewster P (1997) Modelling the Wash from a Ship's Propeller. $\mathrm{PhD}$ thesis, Queen's University of Belfast, Northern Ireland.

Froehlich DC and Shea CC (2000) Screwed-up riprap: Sizing rock linings to resist ship propeller-jets. Proceedings of Joint Conference on Water Resource Engineering and Water Resources Planning and Management 2000, Minnesota, USA.

Fuehrer M and Römisch K (1977) Effects of Modern Ship Traffic on Inland and Ocean Waterways and their Structures. Permanent International Association of Navigation Congresses (PIANC), Brussels, Belgium, bulletin no. 24, section I-3, pp. 79-94.

Hamill GA (1987) Characteristics of the Screw Wash of a Manoeuvring Ship and the Resulting Bed Scour. PhD thesis, Queen's University of Belfast, Northern Ireland.

Hamill GA and Johnston HT (1993) The decay of maximum velocity within the initial stages of a propeller wash. Journal of Hydraulic Research, International Association of Hydraulic Engineering and Research (IAHR) 31(5): 605-613.

Hamill GA, Ryan D and Hughes DAB (2003) The formation of the jet produced by a rotating ship's propeller', Proceedings of the Coasts \& Ports Australasian Conference, paper no. 249, pp. 1-8.

Hamill GA, McGarvey JA and Hughes DAB (2004) Determination of the efflux velocity from a ship's propeller. Proceedings of the Institute of Civil Engineers - Maritime Engineering 157(2): 83-91, http://dx.doi.org/10.1680/maen.2004. 157.2.83.

Hashmi HN (1993) Erosion of a Granular Bed at a Quay Wall by a Ship's Screw Wash. PhD thesis, Queen's University of Belfast, Northern Ireland.

Lam W, Hamill GA, Robinson DJ and Raghunathan S (2012a) Semi-empirical methods for determining the efflux velocity from a ship's propeller. Applied Ocean Research 35(2012): 14-24.

Lam W, Robinson DJ, Hamill GA and Johnston HT (2012b) An effective method for comparing the turbulence intensity from LDA measurements and CFD predictions within a ship propeller jet. Ocean Engineering 52(2012): 105-124.
McGarvey JA (1996) The Influence of the Rudder on the Hydrodynamics and the Resulting Bed Scour of a Ship's Screw Wash. PhD thesis, Queen's University of Belfast, Northern Ireland.

Petersson P, Larson M and Jönsson L (1996) Measurements of the velocity field downstream of an impeller. Journal of Fluids Engineering, Transactions of the American Society of Mechanical Engineers (ASME) 118: 602-610.

Prosser MJ (1986) Propeller Induced Scour. British Ports Association, London, UK, BHRA Report no. 2570, pp. 1-33.

Qurrain RMM (1994) Influence of the sea bed geometry and berth geometry on the hydrodynamics of the wash from a ship's propeller. PhD thesis, Queen's University of Belfast, Northern Ireland.

Stewart DPJ (1992) Characteristics of a Ship's Screw Wash and the Influence of Quay Wall Proximity. PhD thesis, Queen's University of Belfast, Northern Ireland.

Sumer BM and Fredsoe J (2002) The mechanics of scour in the marine environment. Advanced Series in Ocean Engineering, World Scientific 17(x): 423-441.

Verhey HJ (1983) The Stability of Bottom and Banks Subjected to Velocities in the Propeller Jet Behind Ships. Delft Hydraulics Laboratory, Delft, the Netherlands, publication no. 303, pp. 1-11.

Verhey HJ, Blokland T, Bogaerts MP, Volger D and Weyde RW (1987) Experiences in the Netherlands with quay structures subjected to velocities created by bow thrusters and main propellers of mooring and unmooring ships. Permanent International Association of Navigation Congresses (PIANC), Brussels, Belgium, bulletin no. 58, pp. 69-88.

Yeh Y and Cummins HZ (1964) Localized fluid flow measurements with a He-Ne laser spectrometer. Applied Physics Letters 4: 176-178.

\section{WHAT DO YOU THINK?}

To discuss this paper, please email up to 500 words to the editor at journals@ice.org.uk. Your contribution will be forwarded to the author(s) for a reply and, if considered appropriate by the editorial panel, will be published as discussion in a future issue of the journal.

Proceedings journals rely entirely on contributions sent in by civil engineering professionals, academics and students. Papers should be 2000-5000 words long (briefing papers should be 1000-2000 words long), with adequate illustrations and references. You can submit your paper online via www.icevirtuallibrary.com/content/journals, where you will also find detailed author guidelines. 